\title{
Helicobacter pylori infection in healthy people: a dynamic process?
}

\author{
B Meyer, B Werth, C Beglinger, S Dill, J Drewe, W A Vischer, R H Eggers, F E Bauer, \\ G A Stalder
}

\begin{abstract}
Epidemiological studies using serological tests have shown that a large proportion of healthy people have antibodies against Helicobacter pylori (anti-Hp). It is uncertain whether the presence of anti-Hp indicates active infection or only past exposure to the micro-organism. In this study we determined anti-Hp with a specific enzyme linked immunosorbent assay in 100 healthy volunteers who were at the same time investigated for active $\boldsymbol{H}$ pylori infection by means of the ${ }^{13} \mathrm{C}$-urea breath test. Forty nine per cent had a high anti-Hp titre, but only $24 \%$ had active $\boldsymbol{H}$ pylori infection. Our study suggests that a considerable number of healthy people previously infected with $\boldsymbol{H}$ pylori have spontaneously eliminated this microorganism. We suggest that the inability of ulcer patients to eliminate $H$ pylori may be important in the pathogenesis of peptic ulcer disease.
\end{abstract}

Colonisation of the gastric mucosa by Helicobacter pylori is associated with antral gastritis, peptic ulcer disease, and non-ulcer dyspepsia, ${ }^{1}$ but the role of $H$ pylori in the pathogenesis of peptic ulcer disease remains unclear. $^{2-8}$ The methods available for the detection of $H$ pylori infection are microbiological culture, histology, and quick urease tests, which all depend on endoscopy and antral mucosal biopsies. Alternatively, $H$ pylori infection can be detected noninvasively with the urea breath test and with serology. The urea breath test indirectly shows the urease activity of $H$ pylori in the stomach of infected people. ${ }^{910}{ }^{13} \mathrm{C}$-labelled urea ingested orally is hydrolysed in the stomach when $H$ pylori is present, yielding ${ }^{13} \mathrm{CO}_{2}$ which can subsequently be quantitated in the breath. Thus the urea breath test is an elegant, indirect method for detecting gastric $H$ pylori colonisation. Serological testing is an indirect method that has been extensively used to show $H$ pylori infection. ${ }^{11-16}$ At present it is not clear whether in the large proportion (up to $50 \%$ ) of healthy people with antibodies to $H$ pylori (anti-Hp) there is active colonisation of the gastric mucosa by $H$ pylori or whether the antibodies merely represent past exposure to the micro-organism.

The excellent sensitivity and specificity of the urea breath test ${ }^{101718}$ and its simplicity make it an ideal method for screening people for $\mathrm{H}$ pylori colonisation. Thus we evaluated 100 healthy adults with a broad age range for past or active $H$ pylori infection using serology and the urea breath test.

\section{Patients and methods}

\section{PATIENTS}

One hundred people aged 20 to 92 participated in this study. All were healthy and were invited by the investigators to participate. They were recruited from family members, friends, and relatives of the investigators and fellow workers. None had a history of chronic dyspepsia, peptic ulcers, or gastric or other abdominal surgery except for appendicitis; none had taken antacids, a bismuth preparation, or other drugs for dyspepsia within the previous year, and none had taken antibiotics within the three months before the study. The protocol was approved by the University of Basel Ethical Committee and each subject gave written informed consent.

\section{${ }^{13} \mathrm{C}$-UREA BREATH TEST}

All breath tests were performed in the morning after an overnight fast according to the method used and validated previously ${ }^{10}$; Dill et al have shown that the urea breath test has a sensitivity and specificity of $97 \%$ and $100 \%$, respectively. ${ }^{10}$ Briefly, the subjects drank $150 \mathrm{ml}$ of a liquid test meal to delay gastric emptying and subsequently $150 \mathrm{mg}{ }^{13} \mathrm{C}$-urea dissolved in $20 \mathrm{ml}$ of tap water. ${ }^{13} \mathrm{C}$-urea $\left(99 \%{ }^{13} \mathrm{C}\right)$ was purchased as a crystalline substance (Tracer Technologies Inc, Somerville MA, USA). The test meal we used was a $25 \%$ glucose polymeric solution that was prepared as a powder (glucose $4 \mathrm{~g}$, maltose $2 \mathrm{~g}$, polysaccharide $30 \mathrm{~g}$, citric acid $0.2 \mathrm{~g}$ ) in $250 \mathrm{ml}$ bottles and dissolved with $150 \mathrm{ml}$ of tap water immediately before use. Two breath samples were obtained at baseline and then every $15 \mathrm{~min}$ for up to $60 \mathrm{~min}$ and stored in silicon-coated, evacuated $20 \mathrm{ml}$ glass tubes (vacutainers) for later analysis. Excess ${ }^{13} \mathrm{CO}_{2}$ in breath samples was measured by isotope ratio mass spectrometry (Sira 10, VG Instruments $\mathrm{GmbH}$, Wiesbaden, Germany). The results of the breath test are expressed as the percentage of the ${ }^{13} \mathrm{C}$ dose recovered in breath over one hour (area under the curve (AUC) $=\%$ dose $/ 60 \mathrm{~min})$. The breath test was defined as positive if the AUC exceeded $0.5 \%$ dose $/ 60$ min 


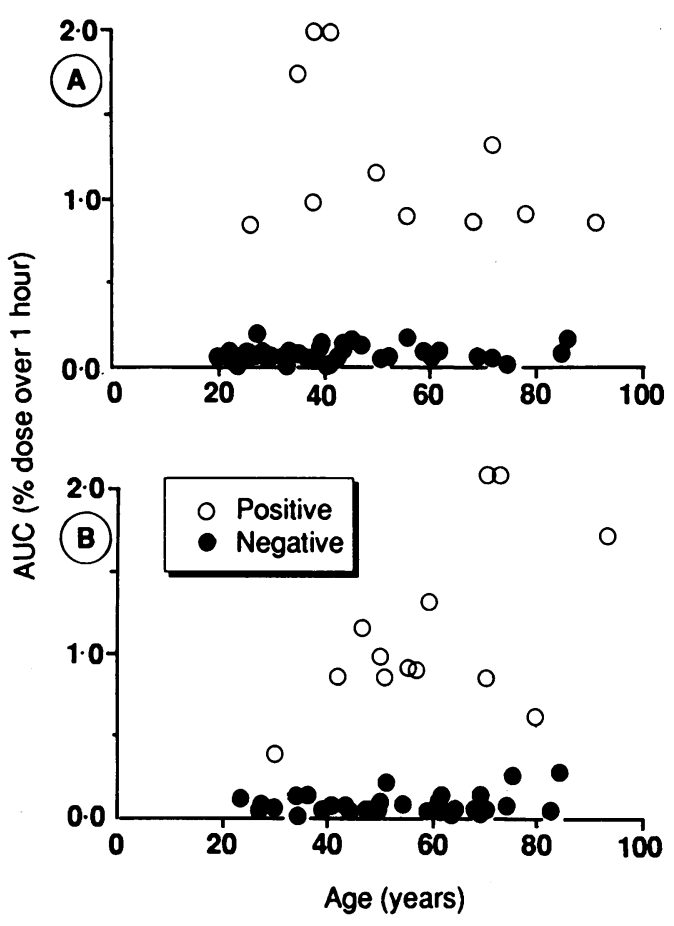

Figure 1: Results of the ${ }^{13} C$-urea breath test in 51 men $(A)$ and 49 women $(B)$ by age. $A U C=$ area under the curve.

ENZYME LINKED IMMUNOSORBENT ASSAY (ELISA) TEST FOR $H$ pylori ANTIBODIES

Sera were tested for IgG antibodies against $H$ pylori (anti-Hp) with a specific ELISA as previously described. ${ }^{16}$ Briefly, the antigen was prepared from stationary phase cultures of $H$ pylori strain $\mathrm{Li} 1103$ that were suspended

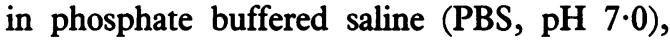
freeze thawed ( $2 x)$, ultrasonicated for $60 \mathrm{~s}$ (B12 sonifier, set at 70) (BronSonic, Bender Hobein AG, Zurich, Switzerland), pelleted at 1.2 per $10^{4} \mathrm{~g}$ for $10 \mathrm{~min}$, resuspended in PBS, and stored in aliquots at $-80^{\circ} \mathrm{C}$. For the ELISA the antigen preparation was diluted with coating buffer to yield a final protein concentration of $1.3 \mu \mathrm{g} / \mathrm{ml}$; $0.1 \mathrm{ml}$ was dispensed into each well of flat bottomed microtitre plates (Immulon MI 29A, Dynatech Laboratories Inc, Alexandria VA, USA) and kept at $4^{\circ} \mathrm{C}$ for 16 hours. The sera, including a negative and a pooled high titre positive control serum, were added to the wells by serial threefold dilutions with PBS (from 1:40 to $1: 87480$ ). The plates were incubated for two hours at $37^{\circ} \mathrm{C}$, washed with an automatic washer (Dynawasher 2, Dynatech Laboratories Inc, Alexandria VA, USA), and incubated at $37^{\circ} \mathrm{C}$ for one hour with gamma-chain specific, 1:1000 diluted, goat antihuman IgG antiserum conjugated with alkaline phosphatase (Tago Inc, Burlingame CA, USA). After washing, p-nitrophenylphosphate (Sigma Chemie $\mathrm{GmbH}$, Deisenhofen, Germany) was added and extinction read after one hour at $405 \mathrm{~nm}$ (Titertek Multiscan MC, Flow Laboratories Co Ltd, Baar, Switzerland). The specificity of anti-Hp antibodies was assessed with multiple absorptions of a rabbit antiserum against $H$ pylori $\mathrm{Li} 1103$ and a high anti-Hp titre human serum pool with a variety of living bacteria, including Escherichia coli (ATCC 25922), Streptococcus sanguis (Li 1345), Salmonella typhimurium (ATCC 13311),

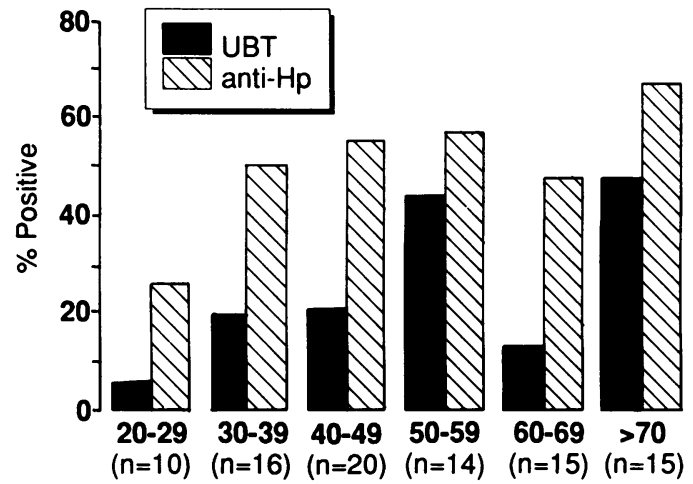

Age groups (years)

Figure 2: Relative percentages of healthy subjects with active $\mathrm{H}$ pylori infection as indicated by a positive ${ }^{3} \mathrm{C}$-urea breath test (UBT) and with serological evidence of past or active infection as indicated by anti-Hp antibodies. The number of persons tested in each age group is given in parentheses.

Campylobacter jejuni (Varia 85A), Campylobacter fetus (K 1578), $H$ pylori (K 1585), and $H$ pylori (Li 1103). Antibodies were almost completely removed by the two $H$ pylori strains, but not absorbed by any of the other micro-organisms tested.

The results are expressed as antibody titres, defined as the reciprocal values of the serum dilution at the intercept of the respective dilution curves with the baseline. ${ }^{19}$ The baseline was defined as extinction measured for the positive control serum at the dilution 1:9720. We have previously shown that a titre of 800 best separated people with and without $H$ pylori infection. ${ }^{16}$ In the present study we have therefore classified people as having anti-Hp if their titre exceeds 800.

\section{STATISTICAL ANALYSIS}

$H$ pylori infection was assessed with serology and the urea breath test. Because the two parameters are interrelated the proportions of people with positive test results were compared with

TABLE I Anti-Hp antibody titres in 100 healthy subjects with positive or negative urea breath tests (UBT)

\begin{tabular}{llll}
\hline & \multicolumn{2}{l}{ Anti-Hp titre $>800$} & \multicolumn{2}{l}{$\begin{array}{l}\text { Anti-Hp titre } \\
<800 \text { and } \\
\text { UBT negative }\end{array}$} \\
\cline { 2 - 4 } & UBT positive & UBT negative & U \\
\hline No & $24(11 \mathrm{M}, 13 \mathrm{~F})$ & $25(10 \mathrm{M}, 15 \mathrm{~F})$ & $51(30 \mathrm{M}, 21 \mathrm{~F})$ \\
Median & 8586 & $1741^{\star}$ & 218 \\
Range & $841-78918$ & $804-29160$ & $40-756$ \\
\hline
\end{tabular}

$\star p<0.001$, significantly lower in comparison to UBT positive group.

TABLE II Results of serology and urea breath test (UBT) in different age groups shown as number with positive results/number tested

\begin{tabular}{lcc}
\hline $\begin{array}{l}\text { Age } \\
\text { group (years) }\end{array}$ & $\begin{array}{l}\text { Anti- } \mathrm{Hp} \\
\text { titre }>800\end{array}$ & $\begin{array}{l}\text { UBT } \\
\text { positive }\end{array}$ \\
\hline $20-29$ & $5 / 20$ & $2 / 20$ \\
$30-39$ & $8 / 16$ & $3 / 16$ \\
$40-49$ & $11 / 20$ & $4 / 20$ \\
$50-59$ & $8 / 14$ & $6 / 14$ \\
$60-69$ & $7 / 15$ & $2 / 15$ \\
$\geqslant 70$ & $10 / 15$ & $7 / 15$ \\
\hline Total & $49 / 100$ & $24 / 100^{\star}$ \\
\hline
\end{tabular}

${ }^{\star} \mathrm{p}<0.0001$. 
McNemar's test for dependent samples. ${ }^{20}$ Antibody titres between different groups were compared with the Mann-Whitney U test.

\section{Results}

Forty nine of the 100 healthy subjects had antiHp titres exceeding 800 ( 21 men, 28 women). Only 24 of these 49 , a significantly $\left(\chi^{2}=18 \cdot 62\right.$, $\mathrm{p}<0.0001$ ) lower proportion, had a positive urea breath test (11 men, 13 women; Fig 1A and B). The other 25 subjects (10 men, 15 women) had anti-Hp only and negative urea breath test results. Their titres were significantly $(p<0.001)$ lower than those of the urea breath test positive subjects (Table I). In 51 of the 100 subjects ( 30 men, 21 women) there was no sign of $H$ pylori infection since they had no anti-Hp and negative urea breath test results (Table I). There was a tendency for both tests to be positive more frequently in elderly subjects (aged over 50 years). The prevalence, however, of anti-Hp positive subjects exceeded that of urea breath test positive subjects in all age groups (Fig 2). There was no difference between men and women. Furthermore, among the six gastroenterologists who participated in this study only two had $H$ pylori infection as shown by positive urea breath test and serology. In the remaining four both tests were negative.

\section{Discussion}

Little is known about the prevalence of $H$ pylori infection in the general population with no gastrointestinal symptoms. The results of our study show that $49 \%$ of a representative sample of the adult Swiss population ${ }^{21}$ have anti-Hp, but only $24 \%$ have active $H$ pylori infection as indicated by a positive urea breath test $(p<0.0001)$. Thus $50 \%$ of previously infected healthy people with anti-Hp may have spontaneously eliminated $H$ pylori.

Our findings are based on two indirect tests. The conclusion, therefore, depends on the specificity and sensitivity of the antibody determination and the urea breath test, respectively. In the present study we classified people as anti-Hp if their titre was above 800 . Similar ELISA titres have been found previously to separate people reliably with and without $H$ pylori infection. ${ }^{12}$ The prevalence of anti-Hppositive healthy subjects found in this study agrees closely with what has been reported: anti-Hp increases with age and occurs in up to $50 \%$ of people aged 60 and older. ${ }^{1011}$

Only 24 out of 49 subjects with high anti-Hp titres had a positive urea breath test and thus active $H$ pylori infection. Twenty five had anti-Hp only and negative urea breath test results. In the studies that have shown that the urea breath test reliably separates patients with and without gastric $H$ pylori colonisation ${ }^{96-18}$ the sensitivity of the urea breath test exceeded $97 \%$ in all of them; among 34 untreated subjects with proved $H$ pylori infection, a false negative urea breath test result occurred in just one. ${ }^{10}$ The prevalence of active $H$ pylori infection was previously investigated in asymptomatic volunteers willing to undergo endoscopy. ${ }^{2-622}$ In the largest of these studies ${ }^{22} H$ pylori infection was proved by a positive culture in $19 \cdot 4 \%$, whereas serology was positive in $33.7 \%$. Graham et al tested healthy volunteers with the urea breath test and reported positive results in $45 \%^{23}$; the antibody state of the participants was, however, not determined.

The results of our study imply that a substantial proportion of healthy people who were infected with $H$ pylori must have eliminated this micro-organism. This phenomenon may have been observed before, but has received little attention. Musgrove et al reported that eight of 39 patients without gastritis and without $H$ pylori had high anti-Hp titres ${ }^{13}$ and Loffeld $e t a l$, in a similar study, found that six of 22 patients without $H$ pylori had anti-Hp titres in the range found in actively infected patients. ${ }^{14}$ Dent $e t a l$, using a different serological test, found high titres in 29 patients in whom $H$ pylori was not detected, and although most of them had gastritis, there were still 10 of 75 patients without gastritis who had positive titres. ${ }^{15}$ All of these results support our hypothesis that $H$ pylori colonisation is a dynamic process with an active phase of infection and subsequent elimination of the micro-organism in at least a proportion of infected people.

Our study may have some relevant clinical and pathophysiological implications. It has been suggested recently that serology might replace endoscopy in the diagnosis of $H$ pylori associated gastritis. ${ }^{14}$ Our study clearly shows that the presence of anti-Hp does not indicate whether a person is actively infected or not.

Finally, we would like to develop a hypothesis which might have relevance for the pathogenesis of peptic ulcer disease. We suggest that healthy people may remain so because they are able to eliminate $H$ pylori, whereas those who will develop ulcers have a defect in the gastric mucosa that makes it susceptible to $H$ pylori colonisation and in turn vulnerable to the acid attack. These patients are unable to eliminate $H$ pylori spontaneously and they remain susceptible to infection with $H$ pylori even after treatment with antibiotics. Thus recurrence or reinfection may take place and be responsible for the high ulcer relapse rates. ${ }^{8}$ This hypothesis needs to be tested by sequential investigation of healthy people. The ${ }^{13} \mathrm{C}$-urea breath test safely permits repeated examinations and is therefore suitable for longterm follow up of healthy people to show the incidence of $H$ pylori infection and the proportion of infected people that will spontaneously eliminate this micro-organism.

We thank Dr Remy Meier, Dr Pius Hildebrand, and Mrs Rita Staehelin for invaluable help in conducting the study and are indebted to Mrs Carita Frei for editorial help and for typing the manuscript.

1 Dooley CP, Cohen H. The clinical significance of Campylobacter pylori. Ann Intern Med 1988; 108: 70-9.

2 Langenberg ML, Tytgat GNJ, Schipper MEI, Rietra PJGM Zanen HC. Campylobacter-like organisms in the stomach of patients and healthy individuals. Lancet 1984; ii: 1348.

3 Pettross CW, Appleman MD, Cohen H, Valenzuela JE Chandrasoma P, Laine LA. Prevalence of Campylobacte pylori and association with antral mucosal histology in subjects with and without upper gastrointestinal symptoms. Dig Dis Sci 1988; 33: 649-53.

4 Barthel JS, Westblom TU, Havey AD, Gonzalez F, Everet ED. Gastritis and Campylobacter pylori in healthy, asymptomatic volunteers. Arch Intern Med 1988; 148: 1149-51. 
5 Fitzgibbons PL, Dooley CP, Cohen H, Appleman MD. Prevalence of gastric metaplasia, inflammation, and Campylobacter pylori in the duodenum of members of a normal population. Am $\mathfrak{f}$ Clin Pathol 1988; 90: 711-4.

6 Gregson DB, Low DE, Cohen MM, et al. The prevalence of Campylobacter pylori gastritis among asymptomatic adults.

7 Marshall BJ, Armstrong JA, McGechie DB, Glancy RJ. Attempt to fulfill Koch's postulates for pyloric Campylobacter. Med F Aust 1985; 142: 436-9,

8 Marshall BJ, Goodwin CS, Warren JR, et al. Prospective double-blind trial of duodenal ulcer relapse after eradication of Campylobacter pylori. Lancet 1988; ii: 1439-42.

9 Graham DY, Klein PD, Evans DJ, et al. Campylobacter pylori detected noninvasively by the ${ }^{13} \mathrm{C}$-urea breath test. Lancet 1987; i: $1174-7$.

10 Dill S, Payne-James JJ, Misiewicz JJ, et al. Evaluation of ${ }^{13} \mathrm{C}$-urea breath test in the detection of Helicobacter pylori and in monitoring the effect of tripotassium dicitrato-bismuthate in monitoring the effect of tripotassium dicitrat

11 Jones DM, Eldridge J, Fox AJ, Sethi P, Whorwell PJ. Antibody to the gastric campylobacter-like organism ('Campylobacter pyloridis') - clinical correlations and distribution in the normal population. $\mathcal{F}$ Med Microbiol 1986; 22: 57-62.

12 Perez-Perez GI, Dworkin BM, Chodos JE, Blaser MJ Campylobacter pylori antibodies in humans. Ann Intern Med 1988; 109: 11-7.

13 Musgrove C, Bolton FJ, Krypczyk AM, et al. Campylobacter pylori: clinical, histological, and serological studies. $\mathcal{F}$ Clin Pylori: clinical, histological

14 Loffeld RJLF, Stobberingh E, Flendrig JA, van Spreeuwel JP, Arends JW. Diagnostic value of an immunoassay to detect anti campylobacter pylori antibodies in non-ulcer dyspepsia. Lancet 1989; i: 1182-5.

15 Dent JC, McNulty CAM, Uff JS, Gear MWL, Wilkinson SP. Campylobacter pylori urease: a new serological test. Lancet 1988; i: 1002

16 Schaub N, Stalder H, Stalder GA, et al. Campylobacter pylori, Gastritis und Ulkuskrankheit. Mikrobiologische, histologische und serologische Untersuchungen. Schweiz Med Wochenschr 1988; 118: 293-301.

17 Bell GD, Weil J, Harrison G, et al. ${ }^{14} \mathrm{C}$-urea breath analysis, a non-invasive test for Campylobacter pylori in the stomach. Lancet 1987; i: 1367-8.

18 Marshall BJ, Surveyor I. Carbon-14 urea breath test for the diagnosis of Campylobacter pylori associated gastritis. f Nucl Med 1988; 29: 11-6.

19 Voller A, Bidwell DE, Bartlett A. The enzyme linked immunosorbent assay (ELISA): a guide with abstracts of microplate applications. Summerfield House, Guernsey: microplate application

20 Bennett BM, Underwood RE. On McNemar's test for the $2 \times 2$ table and its power function. Biometrics 1970; 26: 339 43.

21 Bundesamt fuer Statistik. Statistisches fahrbuch der Schweiz. Zurich: Verlag Neue Zuercher Zeitung, 1988: 14-6.

22 Dooley CP, Cohen H, Fitzgibbons PL, et al. Prevalence of Helicobacter pylori infection and histologic gastritis in asymptomatic persons. N Engl 7 Med 1989; 321: 1562-6.

23 Graham DY, Klein PD, Opekun AR, Boutton TW. Effect of age on the frequency of active Campylobacter pylori infection diagnosed by the ( $\left.{ }^{13} \mathrm{C}\right)$ urea breath test in normal subjects and patients with peptic ulcer disease. $\mathcal{F}$ Infect Dis 1988; 157: and patient 